Ensino, Saúde e Ambiente - V6 (1), pp. 21-34, abr. 2013

\title{
GÊNERO E SEXUALIDADE: COMO OS LICENCIANDOS EM CIÊNCIAS BIOLÓGICAS CONCEBEM ESSES TEMAS?
}

\section{GENDER AND SEXUALITY: HOW TO PRE-SERVICE BIOLOGY TEACHERS DEAL WITH THESE SUBJECTS?}

\author{
Marcelo Borges Rocha ${ }^{1}$ e Gisele Anselmo França ${ }^{2}$ \\ ${ }^{1}$ Doutor em Ciências Biológicas, Centro Federal de Educação Tecnológica Celso Suckow da Fonseca/RJ, \\ rochamarcelo36@yahoo.com.br \\ ${ }^{2}$ Licenciada em Ciências Biológicas, Centro Universitário Augusto Motta - UNISUAM.
}

\begin{abstract}
RESUMO
A presente pesquisa teve como objetivo investigar as representações sociais sobre gênero e sexualidade de alunos de licenciatura do curso de Ciências Biológicas, bem como analisar suas percepções acerca do papel do professor de Biologia na discussão de questões relacionadas a esses temas. Para a coleta dos dados foi utilizado um questionário respondido por 193 estudantes de uma universidade privada do município do Rio de Janeiro. Os conceitos relacionados a gênero e sexualidade, por parte dos alunos, mostraram-se limitados e restritos ao modelo hegemônico estabelecido socialmente. Frente a essas considerações, torna-se necessário aprofundar as discussões acerca do papel do educador na formação dos alunos, visto que, através de sua atuação em sala de aula contribuirá para a construção de novos conceitos no campo da sexualidade.
\end{abstract}

Palavras-chave: gênero; sexualidade; ensino de biologia; orientação sexual.

\begin{abstract}
This research aimed to investigate the social representations of gender and sexuality in pre-service Biology teachers and to examine their perceptions about the role of biology teacher in discussing issues related to that theme. To collect the data we used a questionnaire completed by 193 students from a private university in the city of Rio de Janeiro. The concepts related to gender and sexuality on the part of students were limited and restricted to the hegemonic model established socially. Given these considerations, it is necessary to deepen the discussions on the role of educators in the training of students, since, through his performance in the classroom contribute to the construction of new concepts in the field of sexuality
\end{abstract}

Keywords: gender; sexuality; teaching biology; sexual orientation. 


\section{Introdução}

Questões de gênero e sexualidade são temas recorrentes dentro e fora das salas de aula, e estão presentes na escola permeando atitudes e comportamentos de professores e alunos. Diante disto, os Parâmetros Curriculares Nacionais (Brasil, 1997) recomendam que temas como prevenção de doenças sexualmente transmissíveis e gravidez indesejada sejam discutimos no contexto escolar. Além disso, orientam os professores para que articulem o direito ao prazer, o exercício da sexualidade com responsabilidade, dignidade e afeto próprio e do outro. Os PCN's reconhecem que a proposta de trabalhar essas questões contribui para a prevenção de diversos problemas sociais, dentre eles a discriminação sexual.

Entretanto, abordar temas relacionados à sexualidade não é tarefa fácil, tanto para pais quanto para educadores. Os pais muitas vezes mostram-se temerosos em conversar com seus filhos assuntos como sexo, homossexualidade, doenças sexualmente transmissíveis, gravidez, entre outros, por medo ou por não terem as informações necessárias para orientá-los corretamente. Outro aspecto a ser destacado é que muitos pais pensam que ao abordarem essas questões estarão estimulando precocemente a sexualidade em seus filhos. Na maioria das vezes, recai sobre a escola o papel de educar, orientar e discernir sobre essas questões que fazem parte do cotidiano de crianças e adolescentes que chegam à sala de aula.

É sabido que o tema sexualidade está presente cotidianamente nos espaços escolares, ultrapassando fronteiras disciplinares e de gênero, permeando conversas entre meninos e meninas, professores e professoras e até mesmo, familiares. Além disso, questões relacionadas a gênero e sexualidade são abordadas em sala de aula através do discurso do professor, dos livros didáticos, bem como em músicas e danças que animam festas.

Autores que tem discutido e refletido sobre gênero e sexualidade destacam a importância da inclusão das questões sexuais na sala de aula, e ainda, a forma como devem ser trabalhadas com os alunos (RIBEIRO, 1990; LOURO, 1997). Essa necessidade também é corroborada pelos Parâmetros Curriculares Nacionais (PCN"s) que elencam Orientação Sexual como um dos temas transversais que devem ser inseridos nos conteúdos ensinados na escola. Cabe, portanto, à escola e não mais apenas 
à família, desenvolver uma ação crítica, reflexiva e educativa que proporcione aos educandos uma visão mais ampla e menos preconceituosa no que tange gênero e sexualidade.

No processo de ensino-aprendizagem se reproduzem conflitos decorrentes das relações de poder existentes entre sujeitos com valores, idéias, interesses e hábitos diferentes. Contudo, o ambiente escolar é restrito a um modelo de aluno que deve se enquadrar à norma social: um menino ou uma menina com as características de gênero, heterossexualidade e estrutura familiar compatíveis com o que é esperado pela sociedade (MOLINA e CUNHA, 2010).

\section{Gênero, Sexualidade e Ensino}

Segundo Meyer (2003) o termo gênero refere-se ao processo de construção das distinções entre homens e mulheres através da sociedade e da cultura, com normas, símbolos e leis. Essa visão de gênero focaliza não apenas os papéis sociais dos indivíduos, mas também as diversas práticas sociais. Como diz Louro (1997, p. 26) "gênero pretende se referir ao modo como as características sexuais são compreendidas e representadas ou, então, como são trazidas para a prática social e tornadas parte do processo histórico".

Pretende-se, assim, discutir essas questões sob uma ótica social, visto que na sociedade é que se constroem e se reproduzem as relações entre os sujeitos. As explicações para as desigualdades deveriam ser buscadas não nas diferenças biológicas entre homens e mulheres, mas sim nos contextos sociais, na história, nas condições de acesso aos recursos da sociedade, nas formas de representação (LOURO, 1997).

Foucault (1987) destaca que desde o século XVIII a sociedade vive uma fase de repressão sexual. A partir da ascensão burguesa, o sexo se reduz unicamente à função reprodutora e o casal procriador passou a ser o seu modelo. O comportamento que não corresponde a essa regra assume um caráter de anormalidade e, portanto, é excluído, negado e reduzido ao silêncio. A burguesia restringe as sexualidades negadas a lugares onde possam dar lucros como, por exemplo, as casas de prostituição.

Neste cenário, as feministas introduziram o termo gênero na tentativa de esquivar de um olhar referente exclusivamente as diferenças anatômicas e fisiológicas como justificativa para as desigualdades sociais que se configuravam entre mulheres e 
homens. Com o uso do termo gênero pretendia-se romper com a concepção que atrelava um determinado sexo anatômico a um gênero específico que seria naturalmente correspondente.

Assim como o gênero, o termo sexualidade também não possui um conceito único para sua definição, pois comporta dimensões biológicas, psicossociais e culturais (LOURO, 2001). Desde sua origem, no século XIX, a visão moralista e conservadora ainda se mantém sobre questões relacionadas à sexualidade, atrelando-a exclusivamente à reprodução. Muitas vezes a palavra sexual é utilizada como sinônimo de genital, o que dificulta um entendimento real do seu significado.

Nos PCN"s, a Orientação Sexual é apreendida como sendo de caráter informativo. A sexualidade é idealizada como um dado da natureza, como algo inerente, necessário e fonte de prazer na vida. Ela está relacionada a uma necessidade básica, a potencialidade erótica do corpo, a impulsos de desejo que os adolescentes precisam ser orientados. Alguns trechos ratificam essa idéia:

"A partir da puberdade e das transformações hormonais ocorridas no corpo de meninos e meninas, é comum a curiosidade e o desejo da experimentação erótica a dois." (BRASIL, 1997, p. 82)

"É a partir da puberdade que a potencialidade erótica do corpo se manifesta sob a primazia da região genital, expressando-se na busca do prazer." (BRASIL, 1997, p. 88)

"No trabalho com crianças, os conteúdos devem também favorecer a compreensão de que o ato sexual, assim como as carícias genitais, são manifestações pertinentes à sexualidade de jovens e de adultos, não de crianças. Os jogos sexuais infantis têm caráter exploratório, pré-genital." (BRASIL, 1997, p. 82) 
Nestes trechos percebe-se a presença de indicativos normalizadores da sexualidade. Ela é vista sob o ponto de vista biológico, conectada às funções hormonais. Quanto à experimentação erótica, à curiosidade e ao desejo, estes são considerados comuns, quando a dois. A potencialidade erótica do corpo a partir da puberdade é concebida como centrada na região genital, enquanto que, à infância, só é admitido um caráter exploratório pré-genital. Os conteúdos devem favorecer a compreensão de que o ato sexual, bem como as carícias genitais, só tem pertinência quando manifestados entre jovens e adultos (MOLINA e CUNHA, 2010).

Em outros momentos, articula-se sexualidade e dimensão histórica, por exemplo, ao sugerir que a disciplina História inclua conteúdos relacionados à percepção da sexualidade em diferentes culturas. Entretanto, esta dimensão histórica é pensada como sendo construída em cima de algo naturalmente dado, ou seja, a sexualidade e o sujeito são pensados como essências sob as quais há um investimento da cultura. Nesse sentido, basta analisar o título do primeiro bloco de conteúdos de Orientação Sexual para o terceiro e quarto ciclos a ser trabalhado por todas as disciplinas escolares: "Corpo: matriz da sexualidade".

Diante deste cenário, torna-se relevante discutir a diferença entre o conceito de sexualidade e de sexo. O termo sexo está relacionado à relação sexual, ou seja, o ato em si. Enquanto que sexualidade refere-se muito mais a questões sociais que individuais, sendo conduzida por comportamentos, normas e regras culturais. Relaciona-se a orientação sexual do indivíduo, a afetividade, o prazer, a curiosidade, a atração, entre outros sentimentos que ampliam a dimensão da sexualidade. Porém muitos atrelam sexualidade a sexo de maneira indissociável, tornando difícil a distinção entre os dois (RODRIGUES e SCHEID, 2008).

Temas referentes a sexo e sexualidade, são muitas vezes evitados, tratados como tabus, como obscenos, impuros e cercados de pecado. As instituições, dentre elas a escola, manipulam e controlam o sexo em toda sua dimensão, criando por sua vez, padrões, estereótipos e discriminação. Percebe-se desta forma, que não se pode pensar em sexualidade sem discutir os papéis sócio-culturais, onde inevitavelmente permeiam crenças, atitudes e valores.

Se aos poucos somos convencidos que as questões de gênero e sexualidade devem ser abordadas na sala de aula, devemos também considerar e, igualmente, 
conhecer qual o sujeito que no contexto escolar desempenhará o papel de orientador sexual, sendo este, na maioria das vezes, o professor.

A partir dessas concepções, objetivamos investigar como os conflitos relacionados aos conceitos de gênero e sexualidade são percebidos por futuros professores, que em suas aulas abordarão assuntos relacionados a essa temática. Para aprofundar essa questão, foram aplicados questionários semi-estruturados a estudantes do curso de licenciatura em Ciências Biológicas de uma universidade privada do estado do Rio de Janeiro. Através desses questionários buscou-se conhecer as concepções dos universitários e estabelecer possíveis diálogos entre seus pensamentos e as práticas que serão desenvolvidas no ambiente escolar.

\section{Metodologia}

A pesquisa foi realizada com estudantes do curso de licenciatura em Ciências Biológicas de uma universidade privada do Rio de Janeiro entre os meses de julho e setembro de 2011. A coleta de dados foi feita através de um questionário para investigar as representações sociais sobre gênero e sexualidade desses alunos, bem como analisar suas percepções acerca do papel do professor de Biologia na discussão de questões relacionadas a essa temática. Cento e noventa e três estudantes participaram da pesquisa.

Segundo Lakato e Marconi (2008), o questionário é um importante instrumento para a coleta de dados, estruturado a partir de um conjunto de perguntas que devem ser respondidas por escrito, sem a interferência do pesquisador.

O questionário foi composto por questões abertas, abordando o papel do ensino de ciências na construção da identidade dos alunos e questões fechadas com o objetivo de fazer uma caracterização do perfil sócio cultural, como idade, renda familiar, bairro em que moram, quantas pessoas residem em sua casa, religião praticada, meio de comunicação mais utilizado, entre outras. Ainda nesta parte do questionário as perguntas foram voltadas para investigar a percepção dos estudantes acerca de gênero e sexualidade, buscando saber se há brincadeiras, cores, esportes e profissões específicas para meninos e meninas. Além destas questões, foi observada a concepção que tinham sobre sexo, homossexualidade, entre outras. 
As questões fechadas permitiram traçar um perfil sócio cultural dos graduandos, bem como serviram para caracterizar o aluno com relação a sua percepção de gênero e sexualidade.

As respostas abertas foram analisadas dentro de uma abordagem qualitativa e descritiva caracterizando-se como um estudo de caso. Qualquer investigação social, conforme Minayo (1993) deve contemplar uma característica essencial de seu objeto de estudo: o aspecto qualitativo. Segundo a autora, isso implica em considerar o sujeito de estudo como pessoa que pertence a um determinado grupo ou classe social, possuidor de valores, significados e crenças. Desta forma, na pesquisa qualitativa, os sujeitos são em geral selecionados em função de critérios que não obedecem critérios de amostragem estatística. Nestes estudos, procura-se apreender o sistema, presente de certa maneira em todos os indivíduos da amostra, utilizando para isso, as suas experiências sociais enquanto reveladores de uma cultura.

Para a análise das questões fechadas, utilizou-se um padrão de contagem e aplicação de percentual. Para as questões abertas foram utilizadas planilhas, onde as frases-chave, conceitos-chave e palavras-chave foram analisados conforme sua incidência através do programa Many Eyes, desenvolvido pela IBM Research para análises estatísticas.

\section{Resultados}

\subsection{Caracterização sócio-cultural dos estudantes}

Dos 193 questionários respondidos, 69\% foram de mulheres e $31 \%$ de homens. Entre os questionários das mulheres, a faixa etária predominante ficou entre 20 e 30 anos. Já entre os homens, predominou a faixa etária entre 30 e 40 anos.

Considerando-se a importância de identificar o universo sócio econômico e cultural dos alunos, foi solicitado a eles alguns indicadores a respeito da renda familiar. Levando em conta que o piso mínimo vigente no Brasil em 2011 era de $\mathrm{R} \$$ 545,00, em

$51 \%$ das mulheres entrevistadas a família vivia com 1 a 3 salários mínimos e 37\% com 4 a 7 salários mínimos. Entre os homens, $48 \%$ viviam com renda familiar entre 4 e 7 salários e $28 \%$ entre 1 e 3 salários mínimos. 
Quando foram perguntados sobre a média de pessoas que habitavam em sua residência, $83 \%$ das mulheres e $77 \%$ dos homens afirmaram ter de 2 a 4 pessoas em suas casas. Quanto à localização de suas residências, os resultados mostraram que $66 \%$ das mulheres e $73 \%$ dos homens moravam na Zona Norte e apenas, $1 \%$ das mulheres residia na Zona Sul, não tendo nenhum homem residente nessa região do estado do Rio de Janeiro.

Outro aspecto da constituição familiar, diz respeito à religião, que é predominantemente composta por católicos e evangélicos, $41 \%$ das mulheres se denominaram católicas, $32 \%$ evangélicas; $21 \%$ espíritas e $6 \%$ afirmaram não seguir doutrina nenhuma. Entre os homens, $43 \%$ disseram ser católicos, $20 \%$ evangélicos, $12 \%$ espíritas, $10 \%$ disseram praticar outras religiões e por fim, $15 \%$ afirmaram não ter religião.

Em relação ao meio de comunicação mais utilizado pelo publico feminino para obtenção de informações, a internet teve $54 \%$, a televisão ficou com $32 \%$, os jornais e/ou revistas $12 \%$ e rádio $2 \%$. Já nas respostas dos homens a distribuição ficou da seguinte forma: internet com $68 \%$, televisão com $20 \%$, jornais e/ou revistas com $9 \%$ e rádio com apenas $2 \%$.

Portanto, o perfil sócio econômico da maioria desses alunos é de pessoas que residem na Zona Norte, que têm a internet como principal fonte de informações, seguem predominantemente a doutrina católica ou protestante e possuem uma renda familiar que varia de $\mathrm{R} \$ 545,00$ a $\mathrm{R} \$ 1635,00$ reais ao mês.

\subsection{Percepção sobre gênero e sexualidade}

Após traçar o perfil dos estudantes, iniciou-se a análise envolvendo diretamente as questões relacionadas à concepção de gênero e sexualidade. Nestas afirmativas as respostas deveriam ser assinaladas em "Concordo" e "Não concordo", sendo que em

algumas destas ao assinalar a opção de concordância, deveria ser dada uma sugestão para a questão. Esta etapa iniciou-se buscando saber se há brincadeiras específicas para meninas. Com isso, $47 \%$ das mulheres responderam que concordavam e destas, $100 \%$ apontaram que as meninas devem brincar de casinha e boneca. Em relação aos 
homens, $60 \%$ concordaram que há brincadeiras específicas para meninas e mais uma vez, casinha e boneca foram as escolhidas.

Na sequência, perguntou-se se há cores específicas para homens e mulheres. Entre as mulheres, 92\% discordaram dessa afirmação e $90 \%$ dos homens também discordaram da especificidade da cor em relação ao sexo do indivíduo. Em relação à prática de esportes, $94 \%$ das mulheres afirmaram não existir esporte específico para cada sexo. Já entre os homens, 88\% concordam que sim, sendo o balé relacionado para as meninas e o futebol para os meninos.

A próxima pergunta se refere a existência de profissões específicas para homens e mulheres. Entre as mulheres, $84 \%$ afirmaram não haver essa distinção e 58\% dos homens concordaram, sinalizando que profissões que exijam força devem ser exercidas por homens.

Diante dessas primeiras evidências, observa-se que a percepção dos estudantes sobre as questões de gênero está bastante atrelada ao pensamento hegemônico que estabelece os papéis sociais de homens e mulheres. Tal prerrogativa é concretizada quando, por exemplo, os graduandos, sobretudo os homens, sinalizam que há brincadeiras e esportes específicos para meninos e meninas.

Na pergunta sobre sexo como prova de amor pelo parceiro, $60 \%$ das mulheres e $48 \%$ dos homens concordaram com essa preposição. Ainda em relação ao sexo, foi perguntado se o sexo é uma necessidade física como beber água e comer, apenas $28 \%$ das mulheres concordaram. Já entre os homens houve uma concordância de $72 \%$. Perguntou-se também se crianças e adolescentes devem receber orientação sexual por parte da escola e diante dessa pergunta, 98\% dos homens e 94\% das mulheres concordaram. Foi perguntado em que faixa etária deve-se iniciar o diálogo sobre questões sexuais. Foram dadas três opções: entre 5 e 9 anos, entre 10 e 13 anos ou só a partir dos 14 anos, 58\% dos homens e 52\% das mulheres escolheram entre 10 e 13 anos.

A partir destas respostas, infere-se que os estudantes admitem que o tema orientação sexual deva ser inserido na sala de aula, mas somente a partir dos 10 anos de idade. Entretanto, deve-se refletir sobre o momento, que segundo eles, seria mais propício discutir tais questões. Algumas perguntas podem ser levantadas: Por que não discutir sexualidade antes dos 10 anos? Seria por despreparo ou por medo de estimular 
uma sexualidade precoce? Além disso, fica claro que os homens participantes da pesquisa atribuem ao sexo uma importância fisiológica maior que as mulheres, ao passo que estas relacionam o sexo como prova de amor. Diante disto, pode-se refletir sobre como será a abordagem que este futuro professor dará a questão quando comparada com as futuras professoras.

Outro aspecto investigado diz respeito aos relacionamentos homossexuais. Entre os entrevistados, $39 \%$ das mulheres e $57 \%$ dos homens concordaram com esse tipo de relação entre mulheres. Porém, quando a questão aborda a relação entre dois homens, os resultados mudaram, visto que, $42 \%$ dos homens e $62 \%$ das mulheres concordaram. Por fim, abordou-se a questão da masturbação. Dos participantes, 57\% das mulheres e $80 \%$ dos homens concordaram com a masturbação tanto do homem quanto da mulher. O interessante é que nessa questão houve um considerável índice de pessoas que não quiseram responder, $6 \%$ das mulheres e $3 \%$ dos homens.

Deve-se destacar a partir destes dados, o preconceito em relação à homossexualidade, sobretudo quando se trata do mesmo sexo do estudante questionado, visto que a maioria das alunas não concorda com a homossexualidade feminina e a maioria dos alunos também não concorda com a homossexualidade masculina. Além disso, vale ressaltar a perpetuação dos tabus em relação ao conhecimento do próprio corpo, uma vez que a questão da masturbação foi a que apresentou o maior índice de abstenção.

$\mathrm{Na}$ parte final do questionário foi perguntado sobre o papel do professor e das aulas de ciências na discussão de questões relacionadas a sexo e sexualidade entre crianças e adolescentes. A grande maioria dos participantes sinalizou para o papel fundamental do professor de ciências na informação sobre doenças sexualmente transmissíveis e gravidez precoce. Porém poucos apontaram para o fato de contribuírem para a diminuição do preconceito, da discriminação e da falta de informação no que diz respeito a gênero e sexualidade. Como se observa, a maior preocupação dos entrevistados está relacionada com questões pertinentes ao sexo, no sentido do ato em si. Isso é ratificado através da fala de alguns estudantes:

"O professor de ciências deve se sentir preparado para abordar com os alunos maneiras para evitar a gravidez $e$ doenças como a AIDS". 
"As aulas de Biologia são importantes para ajudar o aluno a perceber a importância de se prevenir contra as DST's e da gravidez indesejada".

"O professor de biologia pode ajudar muito os alunos ensinando a maneira correta de prevenção contra doenças ligadas ao ato sexual".

Através dos questionários aplicados, pode-se perceber que o grupo de alunos não atribui ao ensino de Biologia um papel fundamental na discussão de questões relacionadas a gênero e sexualidade. O que ficou evidente é que o professor de biologia pode contribuir para o esclarecimento de informações sobre sexo apenas no sentido de ato sexual em busca do prazer. Além disso, as respostas vinculadas a gênero e sexualidade mostraram um caráter machista e muitas vezes, discriminador. Deste modo, os termos sexualidade e sexo se confundem e provavelmente, serão trabalhados de maneira equivocada em sala de aula.

Desta forma, evidencia-se que os conceitos e práticas relacionados a gênero e sexualidade por parte dos graduandos mostrou-se limitada e restrita ao modelo hegemônico estabelecido socialmente. Vale ressaltar que o professor de biologia não pode ficar limitado a informações relativas ao aparelho reprodutor, anatomia e fisiologia do corpo humano. Este tipo de abordagem não abrange as necessidades e os interesses de crianças e adolescentes, pois centraliza apenas as questões biológicas e não introduz a vasta dimensão da sexualidade.

\section{Considerações finais}

A maior parte dos estudantes que participaram dessa pesquisa parece não ter a percepção que gênero e sexualidade são construções históricas e culturais. Isto é confirmado através da criação de categorias de brincadeiras, cores, esportes, profissões, enfim aspectos que segregam homens e mulheres dentro da sociedade. Desta forma, esse discurso acaba sendo reafirmado pela escola, através de um currículo oculto que não está aberto a discussão sobre essas questões, reforçando conceitos como obediência feminina, homofobia e conformismo nas relações de gênero e sexualidade. Por exemplo, a aproximação física de dois alunos do mesmo sexo seria interpretada, para a 
maioria dos entrevistados como uma situação desagradável, pois não corresponde ao padrão esperado de heterossexualidade na sala de aula. Ou ainda, as meninas não deveriam estar envolvidas em esportes que exijam força e explosão, mas aqueles que necessitem de delicadeza e leveza.

Os resultados sinalizam para manifestações preconceituosas e de exclusão que muitas vezes não estão explícitas no currículo escolar, mas que se manifestam através de um discurso velado por parte dos professores, pais e da comunidade escolar.

Sabe-se que os professores, inconscientemente, emitem valores referentes a sexualidade. Como consequência, a transmissão da opinião pessoal do educador em sala de aula, pode favorecer ao surgimento de dúvidas, questionamentos e crenças. Considera-se relevante a busca de uma postura profissional e uma formação qualificada para abordar a sexualidade com crianças e adolescentes. Nesta mesma trajetória, o docente necessita refletir seus próprios valores, respeitar a opinião de seus alunos e reconhecer como legítimas e naturais a busca do prazer por parte dos estudantes. O seu papel é orientar, ou seja, mostrar o aluno o lado positivo e negativo de cada atitude e, não determinar o que é certo ou errado. Ele deve debater os diferentes tabus, preconceitos, crenças, buscando com isso, a equidade entre os gêneros, a dignidade individual, a possibilidade do aluno refletir e tomar suas próprias decisões, coerentes com seus valores, no que diz respeito à sua sexualidade e ao outro e a conscientização de sua interação em uma sociedade que incorpora a diversidade.

Dados como os obtidos no presente estudo sinalizam para a necessidade de serem criados mais momentos para discussões acerca da sexualidade, diversidade sexual e gênero dentro da universidade, sobretudo, nos cursos de formação de professores. De acordo com Louro (2003), existe uma grande dificuldade de discutir esses temas dentro do contexto escolar, uma vez que os professores se sentem inseguros e despreparados quando o tema é sexualidade. Além disso, não sabem lidar com as diferentes identidades sexuais e de gênero dos seus alunos. O que poderia justificar esta situação seria o processo histórico de negação às diversidades sexuais e de gênero, principalmente quando estamos diante de um espaço escolar consolidado por perspectivas normatizantes acerca das identidades dos alunos.

A análise dos questionários confirma a hipótese de que os graduandos estão distantes da real aceitação sobre a sexualidade e que parecem interiorizar posições de 
uma tolerância politicamente correta. Louro (1998) considera que mesmo em um mundo repleto de pluralidade cultural, a escola continua silenciando os demais modelos de aceitação sexual em detrimento de um modelo unificador.

Percebe-se, nesse sentido, que os futuros professores precisam tomar consciência sobre questões relacionadas a gênero e sexualidade. E, ainda, necessitam de uma formação acadêmica que propicie discussões, debates e atividades que contribuam para a desconstrução de conceitos preconceituosos e distorcidos da realidade.

Vale destacar, que é importante ensinar nas escolas que não existe uma verdade única sobre sexualidade, o que exige reavaliarmos os mecanismos que constituem a própria sexualidade, muitas vezes vista apenas por perspectivas biológicas e essencialistas. Desta forma, torna-se necessário compor uma nova ética na educação que nos possibilite repensar as relações com o corpo, com o prazer e com o outro.

Portanto, diante dessas primeiras evidências corroboramos a importância da inclusão de questões referentes à sexualidade e gênero na formação inicial dos professores. Essa iniciativa consiste na discussão da sexualidade, enquanto lócus de prazer e vida. Além disso, fornecer subsídios teóricos e pedagógicos para esses professores desenvolverem trabalhos sobre sexualidade e gênero em sala de aula que vão além do caráter estritamente biológico.

\section{Referências bibliográficas}

BRASIL. Ministério da Educação e Cultura. Secretaria de Educação Fundamental. Parâmetros Curriculares Nacionais: terceiro e quarto ciclos, apresentação dos temas transversais. Brasília: MEC/SEF, 1997.

FOUCAULT, M. Vigiar e Punir. 2a ed. Petrópolis: Vozes, 1987.

LAKATO, E M. e MARCONI, M A. Metodologia do trabalho científico. $3^{\mathrm{a}}$ ed. São Paulo: Atlas, 2008.

LOURO, G. L. Currículo, gênero e sexualidade - O normal, o diferente e o excêntrico. In: LOURO, L.G.; NECKEL, F.J., GOELLNER V.S. (Orgs.). Corpo, gênero e sexualidade: um debate contemporâneo na educação. Petrópolis: Vozes, 2003. p. 41-52.

Dossiê Gênero e Educação. Estudos Feministas, São Paulo, v. 9, n. 2, p.

$541-553$, out $/ 2001$.

LOURO, G. L. Sexualidade: lições da escola. In: MEYER, D. (Org.). Saúde e sexualidade na escola. Porto Alegre: Mediação, p. 85-109, 1998. 
LOURO, G. L. Gênero, sexualidade e educação: uma perspectiva pós-estruturalista. $3^{\mathrm{a}}$ ed. Petrópolis: Vozes, 1997.

MANY EYES. Disponível em: http://revista.uepb.edu.br/index.php/qualitas. Acesso em: 25 out. 2011.

MEYER, D. Gênero e Educação: Teoria e Política. In: LOURO, G. et al (Org.). Corpo Gênero e Sexualidade: um debate contemporâneo na educação. Petrópolis: Vozes, 2003, p. 9-27.

MINAYO, M C. O desafio do conhecimento: pesquisa qualitativa em saúde. São Paulo: Hucitec, Abrasco, 1993.

MOLINA, L.P. e CUNHA, M. F. Gênero e sexualidade: construções da diferença na vivência escolar do ensino médio. In: SIMPÓSIO SOBRE ESTUDOS DE GÊNERO E POLÍTICAS PÚBLICAS, 1, 2010, Londrina. Anais..., p. 63-75, 2010.

RIBEIRO, P. R. M. Educação sexual além da informação. $4^{\mathrm{a}}$ ed. São Paulo: E.P.U., 1990.

RODRIGUES, L. R. e SCHEID, N. M. J. Os conhecimentos básicos que os adolescentes possuem sobre sexualidade e o papel do professor de Biologia neste contexto. Revista Educação, v. 33, n. 3, p. 525-542, set./dez. 2008. 